\title{
Relationship between Plasma Levels of Vitamin D in Pregnant Women and Development of Gestational Diabetes Mellitus \\ Ali El Shabrawy Ali ${ }^{1}$, Wael Sabry Noseir ${ }^{1}$, Mohammed El-Hussiny El-Kadosi ${ }^{1}$, Nawras Mohammad Ramadan Alshibani*2 \\ ${ }^{1}$ Department of Obstetrics and Gynecology, Faculty of Medicine, Zagazig University, Sharkia, Egypt. \\ ${ }^{2}$ Department of Obstetrics and Gynecology, Faculty of Medicine, Tripoli University, Tripoli, Libya \\ *Corresponding Author: Nawras Mohammad Ramadan Alshibani, Mobil: 00218918931211, E-mail: raoufelmahdi_86@yahoo.com
}

\section{ABSTRACT}

Background: Gestational diabetes mellitus (GDM) is the leading cause of complications associated with childbirth for both mothers and offspring, and it is considered to be caused by the imbalance between insulin resistance and insulin secretion and contributed maternal hyperglycemia.

This study aimed to assess the relationship between plasma levels of vitamin D in pregnant women and the development of gestational diabetes mellitus.

Patients and Methods: A case-control study was conducted at Gynecology and Obstetrics Department, Zagazig University during the period from August 2020 until April 2021. It included a total of 104 pregnant women. Clinical and obstetrical data were gathered, 25(OH) vitamin D3 total level in $\mathrm{ng} / \mathrm{ml}$ at week gestation (10-12), (24-26), and (34-36). The blood samples were performed by a Cobas 6000.

Results: There is a strong correlation between vitamin D deficiency with the occurrence of gestational diabetes with a cut-off value of $\leq 14.1$ at (10-12) weeks gestation, sensitivity $100 \%$, specificity $97.83 \%$, NPV 100\%, and PPV 93.3\%. Conclusions: There is an inverse association of vitamin D status with gestational diabetes risk.

Keywords: Plasma, Vitamin D, Gestational diabetes mellitus (GDM).

\section{INTRODUCTION}

Gestational diabetes mellitus (GDM) is the leading cause of complications associated with childbirth for both mothers and offspring, and it is considered to be caused by an imbalance between insulin resistance and insulin secretion and contributed to maternal hyperglycemia ${ }^{(\mathbf{1})}$. Among all obstetric complications, a rising prevalence of gestational diabetes mellitus (GDM), a disorder characterized by variable severity of glucose intolerance with onset or first recognition in pregnancy, has been reported over the years, reaching $10-15 \%$ in the world ${ }^{(2)}$.

Physiologically, pregnancy is a diabetogenic condition since the steroid hormones increase and insulin resistance occurs in peripheral tissues, as well as inflammatory cytokines secreted from both adipose tissue and placenta, can contribute to insulin resistance and pathogens of $\mathrm{GDM}^{(\mathbf{3})}$.

Despite a delayed discovery, vitamin D (VD) has emerged as one of the most controversial nutrients and prohormones of the twenty-first century. If its role in calcium metabolism and bone health is undisputed, its influence on other diseases and, more in general, longterm health is debated. Predominantly, VD appears as an intriguing research topic for perinatal investigators dedicated to GDM because its status is easily modified by supplementation ${ }^{(4)}$.

In a meta-analysis of 10 observational studies, it was found that 25-hydroxyvitamin D insufficiency was associated with increased GDM risk in several subpopulations; however, the effect of serum vitamin D levels and subsequent GDM outcomes in the general population has not been definitively determined. Finally, several questions remain unanswered, including the additional confounding factors that may affect the association between serum 25-hydroxyvitamin D and the risk of $\mathrm{GDM}^{(5)}$.Vitamin $\mathrm{D}$ deficiency during pregnancy has been associated with adverse outcomes in pregnant women, such as GDM, urinary tract infection, preeclampsia, and cesarean delivery. Furthermore, infants born to mothers with lower vitamin D levels have been found to have elevated risk of small for gestational age, low birth weight, cardiovascular disease, respiratory illnesses, and type 2 diabetes mellitus ${ }^{(6)}$.

Another potential effect of 1,25 dihydroxyvitamin $\mathrm{D}$ on insulin sensitivity might be exerted via its regulatory role in extracellular calcium concentration and flux through cell membranes. Calcium is essential for insulin-mediated intracellular processes in insulin-responsive tissues such as muscle and fat with a narrow range of intracellular calcium needed for optimal insulin-mediated functions ${ }^{(7)}$.

Changes in intracellular calcium in insulin target tissues may contribute to peripheral insulin resistance via an impaired insulin signal transduction leading to a decreased glucose transporter activity ${ }^{(\mathbf{8})}$. So we designed this study to assess the relationship between plasma levels of vitamin $\mathrm{D}$ in pregnant women and the development of gestational diabetes mellitus.

\section{PATIENTS AND METHODS}

A case-control study was conducted at the Gynecology and Obstetrics Department, Zagazig 
University during the period from August 2020 until April 2021.

\section{Ethical consent:}

Written informed consent was obtained from all participants and the study was approved by the Research Ethics Committee of the Faculty of Medicine, University of Zagazig. Studies have been performed on research with human subjects following the Code of Ethics of the World Medical Association (Declaration of Helsinki).

Inclusion criteria: First-trimester pregnant females in ANC clinic at the time of study period were included in this study.

Exclusion criteria: Previous maternal D.M type I,2, and previous gestational diabetes. Patients refused to enter the study.

The details of clinical and obstetrical history, any medical disorder (DM: type of diabetes, time of diagnosis, type of treatment). Date of last menstrual period for the calculation of gestational age. Previous of history macrosomic infants, unexplained IUFD, neonatal death, and any medical illness were reported was performed for detection of any systemic disease and measuring vital signs, height, and weight of the patient to calculate BMI. Maternal BMI was measured by dividing the weight in kilograms by the square of the height in meters.

Investigations; Serum $25(\mathrm{OH})$ vitamin $\mathrm{D} 3$ total level in $\mathrm{ng} / \mathrm{ml}$ at week gestation (10-12), (24-26), and (34-36). The blood samples were performed by a Cobas 6000 . This assay is intended for the quantitative determination of the total 25hydroxyvitamin D in human serum and plasma. This assay is to be used as an aid in the assessment of vitamin D sufficiency. The electrochemiluminescence binding assay is intended for use on Elecsys and Cobas immunoassay analyzers.

Serum 25(OH) vitamin D3 total level was measured (A serum blood level of at least $30 \mathrm{ng} / \mathrm{ml}$ was considered sufficient. $20-30 \mathrm{ng} / \mathrm{ml}$ as insufficient. Less than $20 \mathrm{ng} / \mathrm{ml}$ as deficient. Less than $7 \mathrm{ng} / \mathrm{ml}$ as severe deficiency $(\mathrm{nmol} / \mathrm{l}=2.469 \times \mathrm{ng} / \mathrm{ml})$.

\section{Maternal screening for GDM:}

Using FBS and 2 hours postprandial blood glucose level is done during the period of hospital admission from (24-28weeks), if the patient had the high-risk criteria so, screening at once, if the level is $>140 \mathrm{mg} / \mathrm{dl}$, so the screening is positive and $75 \mathrm{gm} \mathrm{2-}$ hour oral glucose tolerance test (OGTT). A fasting blood glucose sample was obtained. It provides a baseline for comparing other glucose values, the patient will be asked to drink a sweet liquid containing a measured amount of glucose. For the glucose tolerance test, she will drink 75 grams.

Blood samples were collected at timed intervals of 1,2 , and sometimes 3 hours after drinking the glucose. Pregnant diabetics were diagnosed with at least two values of plasma glucose levels exceeding the carpenter and coustan criteria by the American Diabetes Association.

Follow up of our patients every 2 weeks till 36 weeks, then every week till delivery, in each visit. Maternal investigations: (HB, Rh. typing, AST, ALT, Urea, Creatinine, Urine analysis \& coagulation profile, FBS, HbA1c, and PPBS). Trans-abdominal ultrasound examination for fetal viability, gestational age confirmation, measurement of fetal abdominal circumference (AC), and calculation of expected fetal birth weight (EFBW) before delivery. Doppler US to assess placental vascularization and calculate flow indices. Neonatal birth weight is measured in grams upon delivery.

\section{Statistical Analysis}

Statistical analysis was done using SPSS software version 27 (IBM, 2020). Data were presented in tables and figures. Pearson's chi-squared test and chi-square for linear trend were used to analyze qualitative variables as appropriate. Student's t-test and Mann Whitney U test were used to analyze quantitative variables as appropriate. Pearson's correlation coefficient and Spearman's correlation coefficient were used to exploring linear relationships between quantitative variables as appropriate. A P-value of $<0.05$ was accepted as statistically significant.

\section{RESULTS}

Table (1): Basic characteristics of the studied groups: $(n=104)$.

\begin{tabular}{||l|c|c|c|c||}
\hline \multicolumn{1}{|c|}{ Variables } & GDM group $(\mathbf{n}=\mathbf{5 2})$ & Control group $(\mathbf{n}=\mathbf{5 2})$ & Test of sig. & P \\
\hline \hline Age (years): Mean \pm SD & $27.4 \pm 6.6$ & $28.3 \pm 4.9$ & T 0.8 & 0.4 \\
\hline $\begin{array}{l}\text { Gestational age at delivery (weeks): } \\
\text { Mean } \pm \text { SD }\end{array}$ & $35.8 \pm 1.2$ & $38.0 \pm 2.7$ & $\mathrm{~T}$ & 0.07 \\
\hline BMI $\left(\mathbf{k g} / \mathbf{m}^{2}\right)$ : Mean \pm SD & $30.0 \pm 2.4$ & $28.5 \pm 4.3$ & $\mathrm{~T} 2.2$ & $\mathbf{0 . 0 3} *$ \\
\hline
\end{tabular}

* Statistically significant.

Table (1), showed that there was a statistically significant difference between GDM and control groups in BMI. Figurer (1), showed that there was a statistically significant difference between GDM and control groups in obstetric history. The GDM group had significantly more previous miscarriages than the control group.

- $\quad$ Nullipara=P0. Primipara=P1. Multipara=P1. 


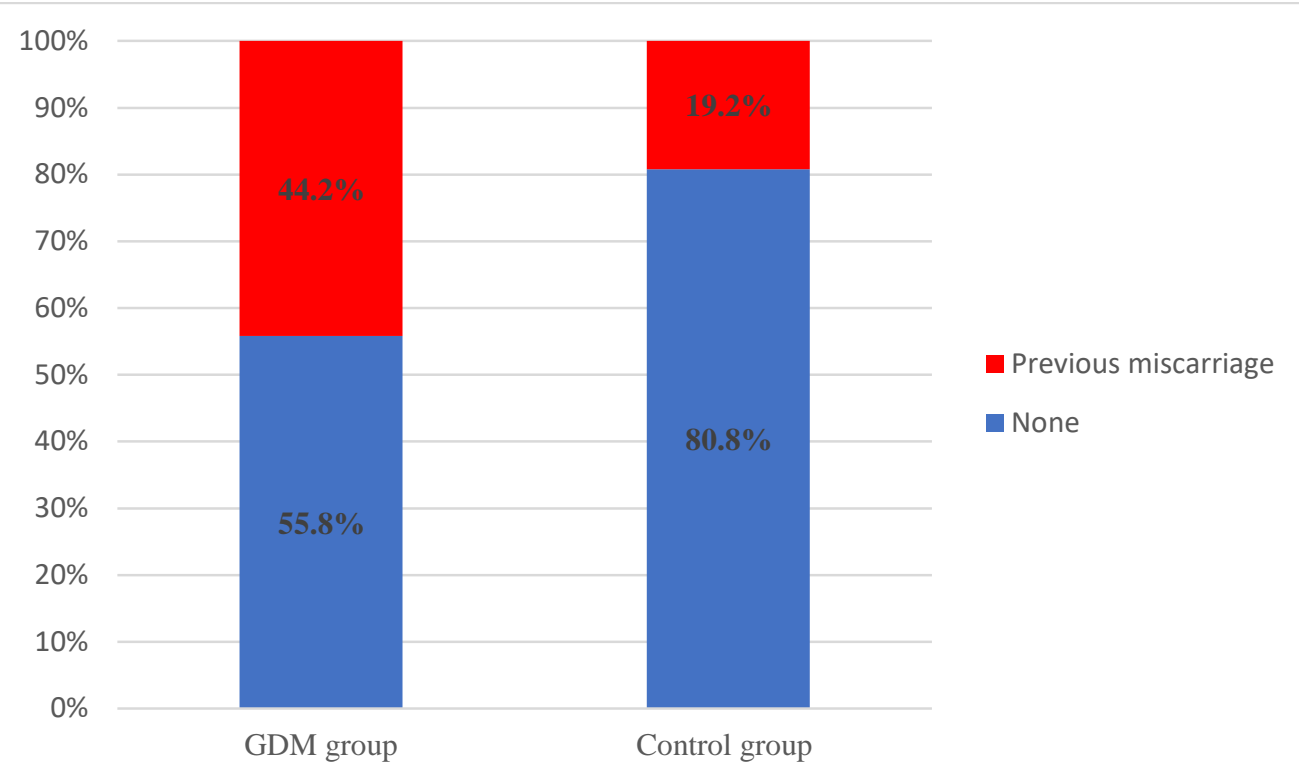

Figure (1): Previous miscarriage in the studied groups: The GDM group had significantly more previous miscarriages than the control group.

Table (2): Vitamin D levels in the studied groups.

\begin{tabular}{|c|c|c|c|c|}
\hline Variables & GDM group $(n=52)$ & Control group $(\mathrm{n}=52)$ & Test of sig. & $\mathbf{P}$ \\
\hline \multicolumn{5}{|c|}{$(10-12)$ week } \\
\hline $\begin{array}{l}\text { Vitamin D }(\mathrm{ng} / \mathrm{ml}): \\
\text { Mean } \pm \text { SD } \\
\text { Median }\end{array}$ & $\begin{array}{c}17.5 \pm 4.8 \\
14.5 \\
\end{array}$ & $\begin{array}{c}24.7 \pm 5.6 \\
23.4\end{array}$ & $\begin{array}{c}\text { MW } \\
9.8\end{array}$ & $<0.001 * *$ \\
\hline $\begin{array}{l}\text { Level of Vitamin D: } \\
\text { Deficient }(<20) \\
\text { Insufficient }(20-30) \\
\text { Sufficient }(>30)\end{array}$ & $\begin{array}{c}32(61.5 \%) \\
16(30.8 \%) \\
4(7.7 \%) \\
\end{array}$ & $\begin{array}{c}17(32.7 \%) \\
28(53.8 \%) \\
7(13.5 \%) \\
\end{array}$ & $\begin{array}{c}\chi^{2} \\
4.9\end{array}$ & $0.005 *$ \\
\hline \multicolumn{5}{|l|}{ (24-26) week } \\
\hline $\begin{array}{l}\text { Vitamin D }(\mathrm{ng} / \mathrm{ml}): \\
\text { Mean } \pm \text { SD } \\
\text { Median }\end{array}$ & $\begin{array}{c}15.5 \pm 3.8 \\
12.5\end{array}$ & $\begin{array}{c}23.7 \pm 4.6 \\
22.4\end{array}$ & $\begin{array}{c}\text { MW } \\
9.6\end{array}$ & $<0.001 * *$ \\
\hline $\begin{array}{l}\text { Level of Vitamin D: } \\
\text { Deficient }(<20) \\
\text { Insufficient }(20-30) \\
\text { Sufficient }(>30)\end{array}$ & $\begin{array}{c}30(57.6 \%) \\
17(32.7 \%) \\
5(9.7 \%)\end{array}$ & $\begin{array}{c}17(32.7 \%) \\
28(53.8 \%) \\
7(13.5 \%)\end{array}$ & $\begin{array}{l}\chi^{2} \\
4.9\end{array}$ & $0.005 *$ \\
\hline \multicolumn{5}{|l|}{$(34-36)$ week } \\
\hline $\begin{array}{l}\text { Vitamin D }(\mathrm{ng} / \mathrm{ml}): \\
\text { Mean } \pm \text { SD } \\
\text { Median }\end{array}$ & $\begin{array}{c}15.9 \pm 3.8 \\
11.9 \\
\end{array}$ & $\begin{array}{c}29.9 \pm 5.6 \\
22.44\end{array}$ & $\begin{array}{c}\text { MW } \\
9.6\end{array}$ & $<0.001 * *$ \\
\hline $\begin{array}{l}\text { Level of Vitamin D: } \\
\text { Deficient }(<20) \\
\text { Insufficient }(20-30) \\
\text { Sufficient }(>30)\end{array}$ & $\begin{array}{l}28(53.8 \%) \\
19(36.5 \%) \\
7(13.5 \%)\end{array}$ & $\begin{array}{c}16(30.7 \%) \\
30(57.6 \%) \\
6(11.5 \%)\end{array}$ & $\begin{array}{l}\chi^{2} \\
4.9\end{array}$ & $0.005^{*}$ \\
\hline
\end{tabular}

* Statistically significant.

** High statistical significance.

Table (2), showed that there was a significant difference between GDM and control groups in the vitamin D level. The GDM group had significantly lower vitamin D than the control group. Almost twothirds of the GDM group had deficient vitamin D levels, and only $7.7 \%, 9.7 \%$, and $13.5 \%$ had sufficient vitamin D levels.

Figurer (2), showed that there was a significant association between gestational age and vitamin D level. Deficient vitamin D patients had higher gestational age compared to other patients. 


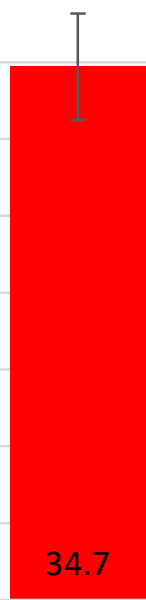

Deficient

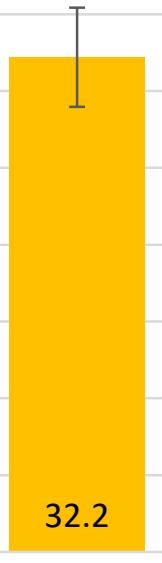

Insufficient

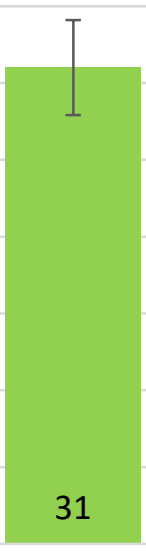

Sufficient

Vitamin D level

Figure (2): Vitamin D level in the studied groups: a statistically significant association between gestational age and vitamin D level. Deficient vitamin D patients had higher gestational age compared to other patients.

Table (3): Maternal and baby outcome distribution between studied groups.

\begin{tabular}{|c|c|c|c|c|c|c|}
\hline \multicolumn{3}{|c|}{ Variables } & $\begin{array}{c}\text { GDM group } \\
(n=52)\end{array}$ & $\begin{array}{c}\text { Control group } \\
(\mathrm{n}=52)\end{array}$ & Test of sig. & $\mathbf{P}$ \\
\hline \multirow{4}{*}{ Term } & \multirow{2}{*}{ Preterm } & $\mathbf{N}$ & 10 & $\mathbf{3}$ & & \\
\hline & & $\%$ & $17.6 \%$ & $5.8 \%$ & & \\
\hline & \multirow{2}{*}{ Full-term } & $\mathbf{N}$ & 42 & 49 & 5.11 & $0.026 *$ \\
\hline & & $\%$ & $82.4 \%$ & $94.2 \%$ & & \\
\hline \multirow{4}{*}{ Mode of Delivery } & \multirow{2}{*}{ CS } & $\mathbf{N}$ & 41 & 30 & & \\
\hline & & $\%$ & $80.4 \%$ & $57.6 \%$ & & \\
\hline & \multirow{2}{*}{ VD } & $\mathbf{N}$ & 11 & 22 & 9.83 & 0.003* \\
\hline & & $\%$ & $19.6 \%$ & $42.4 \%$ & & \\
\hline \multirow{4}{*}{ PPH } & \multirow{2}{*}{ No } & $\mathbf{N}$ & 50 & 52 & & \\
\hline & & $\%$ & $96.1 \%$ & $100.0 \%$ & & \\
\hline & \multirow{2}{*}{ Yes } & $\mathbf{N}$ & 2 & 0 & 5.84 & $0.022 *$ \\
\hline & & $\%$ & $3.9 \%$ & $0.0 \%$ & & \\
\hline \multirow{4}{*}{ Macrosomia } & \multirow{2}{*}{ No } & $\mathbf{N}$ & 41 & 51 & & \\
\hline & & $\%$ & $80.4 \%$ & $98.02 \%$ & & \\
\hline & \multirow{2}{*}{ Yes } & $\mathbf{N}$ & 11 & 1 & 2.31 & 0.12 \\
\hline & & $\%$ & $19.6 \%$ & $1.98 \%$ & & \\
\hline \multirow{4}{*}{ NICU } & \multirow{2}{*}{ No } & $\mathbf{N}$ & 41 & 51 & & \\
\hline & & $\%$ & $80.4 \%$ & $98.02 \%$ & & \\
\hline & \multirow{2}{*}{ Yes } & $\mathbf{N}$ & 11 & 1 & 2.31 & 0.12 \\
\hline & & $\%$ & $19.6 \%$ & $1.98 \%$ & & \\
\hline \multicolumn{2}{|c|}{ APGAR1 } & & $5.72 \pm 0.89$ & $6.68 \pm 1.06$ & -4.993 & $0.00 * *$ \\
\hline \multicolumn{2}{|c|}{ APGAR2 } & & $7.88 \pm 0.95$ & $9.18 \pm 0.84$ & -1.723 & \begin{tabular}{|l|}
0.088 \\
\end{tabular} \\
\hline
\end{tabular}

Table (3), showed that low APGAR1, preterm, CS delivery type, and PPH were significantly associated with the gestation diabetes group. 
Table (4): Association between Vitamin D level and laboratory data of GDM group.

\begin{tabular}{|c|c|c|c|c|c|}
\hline \multirow{2}{*}{ Variables } & \multicolumn{3}{|c|}{ Vitamin D level } & \multirow{2}{*}{ Test of sig. } & \multirow{2}{*}{$\mathbf{P}$} \\
\hline & Deficient & Insufficient & Sufficient & & \\
\hline $\begin{array}{l}\text { Hemoglobin }(\mathrm{gm} / \mathrm{dl}): \\
\text { Mean } \pm \text { SD }\end{array}$ & $11.4 \pm 1.1$ & $10.8 \pm 1.1$ & $11.1 \pm 1.4$ & $\begin{array}{l}\mathrm{KW} \\
2.7\end{array}$ & 0.3 \\
\hline $\begin{array}{l}\text { Fasting blood glucose }(\mathrm{mg} / \mathrm{l}) \text { : } \\
\text { Mean } \pm \text { SD }\end{array}$ & $130.6 \pm 7.2$ & $137.4 \pm 3.8$ & $154.5 \pm 22.1$ & $\begin{array}{c}\mathrm{KW} \\
2.4\end{array}$ & 0.3 \\
\hline $\begin{array}{l}\text { Postprandial blood glucose } \\
(\mathrm{mg} / \mathrm{dl}): \\
\text { Mean } \pm \text { SD }\end{array}$ & $243.8 \pm 54.8$ & $250.4 \pm 8.3$ & $326.0 \pm 9.6$ & $\begin{array}{c}\mathrm{KW} \\
3.0\end{array}$ & 0.2 \\
\hline $\begin{array}{l}\text { Hemoglobin A1C (\%): } \\
\text { Mean } \pm \text { SD }\end{array}$ & $7.5 \pm 1.1$ & $7.9 \pm 1.3$ & $8.0 \pm 1.2$ & $\begin{array}{c}\mathrm{KW} \\
1.6 \\
\end{array}$ & 0.4 \\
\hline
\end{tabular}

Table (4), showed that no statistically significant association between Vitamin D level and laboratory data of the GDM group.

\section{DISCUSSION}

The current study revealed that the mean age of the studied groups was $(27.4 \pm 7.1)$ years in GDM and $(28.3 \pm 5.40)$ years in the control one with no statistical difference in maternal age between the two groups. While in Salge et al. $^{\left({ }^{(9)}\right.}$ the mean age of the women studied was $(28.5 \pm 5.71)$ years.

In the present study, the BMI of the studied groups was $(30.5 \pm 2.4)$ in GDM patients and (28.5 4.3) in the control group which had a statistically significant difference between both groups. The GDM group had a significantly higher BMI than the control group.

The study of Soliman et $_{\text {al }}$ (10), $^{(1)}$ assessed BMI and found that fifty-five percent of DM, 38\% of GDM, and $25.6 \%$ of controls were obese $(p<0.001)$.

The present study revealed that $88.5 \%$ and $82.7 \%$ of both groups were multigravidas in respectively. There was a higher proportion of multigravida than primigravida women $6 \%$, and $9 \%$ respectively) among women with GDM which was following another study in which $16 \%$ of the studied group were primigravida, and (82\%) were multiparous ${ }^{(\mathbf{1 0})}$.

The present study revealed that $44.2 \%$ of GDM and $19.2 \%$ of the control group has a previous history of abortion.

In the current study GDM group delivered at gestational age $>34$ weeks and $4 \%$ of them was preterm and as regard mode of delivery $80.4 \%$ of GDM delivered by C.S and $57.6 \%$ of the control group delivered by CS.

Another study by Shefali $\boldsymbol{e t}$ al..$^{(11)}$ found that preterm delivery was $6(7.6 \%)$ in PGDM and 12 $(8.2 \%)$ in GDM.

The current study showed a statistically significant difference between both groups in vitamin D levels. The GDM group had significantly lower vitamin $\mathrm{D}$ than the control group. Almost two-thirds of the GDM group had deficient vitamin D levels, and only $7.7 \%$ had sufficient vitamin D levels.
It was found that at early pregnancy, vitamin D status was inversely associated with the risk of GDM. Women, who had vitamin D deficiency in early pregnancy, had a 3.3 fold higher risk of developing $\mathrm{GDM}^{(\mathbf{1 2})}$. These findings are similar to some previous studies that investigated vitamin D status and GDM risk as Zhang $\boldsymbol{e t} \boldsymbol{a l} .{ }^{(\mathbf{1 3})}$ but were different than others. This research reported that vitamin D deficiency was associated with a 3.3 - fold increased risk of subsequent GDM [95\% CI $0.988-1.003^{(13)}$.

Two independent meta-analyses of observational studies were done by Maestro et al. ${ }^{(\mathbf{1 4})}$ and Bland et $\boldsymbol{a l}^{(\mathbf{1 5 )}}$ reported a $38-61 \%$ higher risk of GDM among women with vitamin D deficiency (total $25[\mathrm{OH}] \mathrm{D}<50 \mathrm{nmol} / \mathrm{l})$. More recently, Lacroix et al. ${ }^{(\mathbf{1 2})}$ reported that lower first trimester $25[\mathrm{OH}] \mathrm{D}$ concentrations were associated with a higher risk of developing GDM (OR 1.48 per decrease of one SD in 25[OH]D concentration, $\mathrm{P}=0.04)$ Bland et al. ${ }^{(\mathbf{1 3})}$ However, in other studies, associations of vitamin D status with GDM risk were not observed. Baker $\boldsymbol{e t}$ $\boldsymbol{a l} .^{(16)}$, reported that women with vitamin D deficiency, in early pregnancy, did not have a significantly higher risk of GDM compared with women who did not have vitamin D deficiency (OR 0.78 [95\% CI 0.22, 2.78]). Similarly, researchers did not observe associations of vitamin D deficiency with the risk of GDM in other studies conducted in Korea, North England, and Australia $^{(17)}$

Recently, Zhou et $\boldsymbol{a l} .{ }^{(\mathbf{1 8})}$, reported that the prevalence of GDM was higher among women with high $25[\mathrm{OH}] \mathrm{D}(\geq 30 \mathrm{ng} / \mathrm{ml})$ concentrations compared with women low and medium groups (OR 1.02 95\% CI 1.00, 1.03).

Relatively few previous studies have considered the different constituents of a total $25[\mathrm{OH}] \mathrm{D}$ concerning disease risk. There are two forms of vitamin D, vitamin D2 (ergocalciferol), a synthetic form, and vitamin D3 (cholecalciferol), obtained through diet and exposure of skin to sunlight. Unless 
otherwise specified, vitamin D status refers to the total D2 and D3 concentrations. While both forms of vitamin $\mathrm{D}$ utilize the same enzymes in their metabolic pathways, the differences in their side chains (vitamin D2 contains a double bond between carbons 22 and 23, and a methyl group on carbon 24) result in the production of unique metabolites of differing potencies and bio effectiveness ${ }^{(\mathbf{1 9})}$.

\section{CONCLUSIONS}

There is an inverse association of vitamin D status with gestational diabetes risk. Because of the high level of vitamin D deficiency and insufficiency found among 48 pregnant women $(92.3 \%)$; exposure to sunlight which is the main source of vitamin D on a specific day time is very important. Early pregnancy $25(\mathrm{OH}) \mathrm{D} 3$ assessment is advised. Research should continue on the effectiveness of supplementation and possible side effects of vitamin D supplementation on mothers during pregnancy.

\section{REFERENCES}

1. Khanpaye A, Madmoli Y, Riahipour B et al. (2019): Evaluation of Knowledge, Attitude and Performance Regarding Gestational Diabetes Mellitus in Southwest of Iran. Journal of Pharmaceutical Research International, 28(4): 1-6.

2. Visconti F, Quaresima P, Chiefari E et al. (2019): First Trimester Combined Test (FTCT) as a Predictor of Gestational Diabetes Mellitus. https://www.mdpi.com/1660-4601/16/19/3654/htm

3. Lindqvist $\mathbf{S}$ (2017): Low maternal circulating levels of vitamin $\mathrm{D}$ as a potential determinant in the development of gestational diabetes mellitus. Journal of Endocrinological Investigation, 12: 1-9.

4. Lanzone S (2015): Potential impact of maternal vitamin D status on obstetric well-being. Journal of Endocrinological Investigation, 6: 1-8.

5. Ronksley P, Tough S, Beirne $M$ et al. (2013): Association between maternal serum 25hydroxyvitamin D level and pregnancy and neonatal outcomes: systematic review and meta-analysis of. BMJ., 1169: 1-14.

6. Ede G, Keskin U, Yenen M et al. (2019): Lower vitamin D levels during the second trimester are associated with developing gestational diabetes mellitus : an observational cross-sectional study Lower vitamin $\mathrm{D}$ levels during the second trimester are associated with. Gynecological Endocrinology, 1: 1-4.

7. Wright J, Saunders D, Dai C et al. (2020): Decreased pancreatic acinar cell number in type 1 diabetes. Diabetologia, 63: 1418-1423.
8. Zemel $M$ (2021): Nutritional and endocrine modulation of intracellular calcium: implications in obesity, insulin resistance and hypertension. Molecular and Cellular Effects of Nutrition on Disease Processes, 188: 129-136.

9. Salge A, Rocha K, Xavier $R$ et al. (2012): Macroscopic placental changes associated with fetal and maternal events in diabetes mellitus. Clinics, 67(10): 1203-1208.

10. Soliman A, Salama H, Al Rifai H et al. (2018): The effect of different forms of dysglycemia during pregnancy on maternal and fetal outcomes in treated women and comparison with large cohort studies. Acta Bio Medica: Atenei Parmensis, 89(5): 11-16.

11. Shefali A, Kavitha $M$, Deepa $R$ et al. (2006): Pregnancy outcomes in pre-gestational and gestational diabetic women in comparison to non-diabetic women-A prospective study in Asian Indian mothers (CURES35). The Journal of the Association of Physicians of India, 54(8): 613-618.

12. Lacroix M, Battista M, Doyon M et al. (2014): Lower vitamin D levels at first trimester are associated with a higher risk of developing gestational diabetes mellitus. Acta Diabetologica, 51(4): 609-616.

13. Zhang C, Qiu C, Hu F et al. (2020): Maternal plasma 25-hydroxyvitamin D concentrations and the risk for gestational diabetes mellitus. PloS One, 3(11): 3753-58.

14. Maestro B, Molero S, Bajo $S$ et al. (2019): Transcriptional activation of the human insulin receptor gene by 1, 25-dihydroxy vitamin D3. Cell Biochem Funct., 20(3): 227-232.

15. Bland R, Markovic D, Hills $C$ et al. (2019): Expression of 25-hydroxyvitamin D3-1 $\alpha$-hydroxylase in pancreatic islets. The Journal of Steroid Biochemistry and Molecular Biology, 89: 121-125.

16. Baker A, Haeri S, Camargo J et al. (2012): Firsttrimester maternal vitamin $\mathrm{D}$ status and risk for gestational diabetes (GDM) a nested case-control study. Diabetes/Metabolism Research and Reviews, 28(2): 164-168.

17. Park S, Yoon H, Ryu H et al. (2019): Maternal vitamin $\mathrm{D}$ deficiency in early pregnancy is not associated with gestational diabetes mellitus development or pregnancy outcomes in Korean pregnant women in a prospective study. Journal of Nutritional Science and Vitaminology, 60(4): 269-275.

18. Zhou J, Su L, Liu M et al. (2014): Associations between 25-hydroxyvitamin D levels and pregnancy outcomes: a prospective observational study in southern China. European Journal of Clinical Nutrition, 68(8): 925-930.

19. Grimes D, Schulz K (2017): Bias and causal associations in observational research. The Lancet, 359(9302): 248-252. 